\title{
Factors affecting the accounting information quality in commercial enterprises in Hochiminh City
}

\author{
Huynh Xuan Hiep, Nguyen Dong Phuong, \\ Faculty of Finance \& Accounting \\ Hochiminh City University of Food Industry \\ xuanhieptckthufi@gmail.com
}

\begin{abstract}
The accounting information quality has become an urgent need in the whole society and all fields. In particular, the accounting information quality in trading companies is being paid attention to. To achieve this goal, it is necessary to have studies to understand the factors, as well as the extent to which these factors affected the accounting information quality. To conduct the research, the authors have used a combination of qualitative and quantitative research methods. Research results have pointed out that 5 factors affecting the accounting information quality in trading companies in Hochiminh City, which are the Involvement of managers (QT), Tax policy (TU), qualification of accountants (TD), Application of information technology $(\mathrm{CN})$, and Internal control system (KS).
\end{abstract}

Index Terms-quality, accounting information, business, trade, trading companies.

\section{INTRODUCTION}

$\mathrm{R}$ ESEARCH on "Factors affecting the accounting information quality in trading companies in Hochiminh City" is implemented with specific objectives:

(1) Determining the factors affecting the accounting information quality in trading companies in Hochiminh City.

(2) Measuring the influence of factors on the accounting information quality in trading companies in Hochiminh City.

(3) Proposing management implications to improve the accounting information quality of trading companies in Hochiminh City.

The study was conducted by collecting data through a survey questionnaire with a sample size of 130 companies in Hochiminh City, and at the same time applying the method of testing the reliability of the scale, exploratory factor analysis (EFA), and linear regression to evaluate the influence of factors on the accounting information quality in trading companies in Hochiminh City.

Research results have identified five factors that favorably affect $(+)$ the accounting information quality in trading companies in Hochiminh City, in which the most influential factor is: The involvement of managers $(\beta=0.306)$; follows are factors: Tax policy $(\beta=0.278)$; Accounting staff qualification $(\beta=0.272)$; Information technology application $(\beta=$ $0.229)$. The factor: Internal control system $(\beta=0.162)$ is the weakest influence.

Most companies in Vietnam are small and medium-sized ones, so the accounting information quality is very simple, the input data is sketchy, not systematic, the content is outdated and duplicated. The technical method applied is very simple, has not paid attention to exploiting modern information processing facilities and techniques, has not yet created the connection, stability, and orientation between informa- tion serving management. With the information needs of users, the level of knowledge about accounting information of managers is still limited, there is no specialized staff in handling and providing accounting information. Besides, the accounting information quality scale of previous studies was built by inheriting the scales from overseas studies, it is necessary to adjust the scale to suit companies in Vietnam.

From the gaps of previous studies, the authors have identified the research direction "Factors affecting the accounting information quality in companies in Hochiminh City." Therefore, the study of the authors has no overlap compared with the studies of the previous authors.

This study contributes to generalizing and developing theoretical issues about the accounting information quality, theoretically contributing to building models of factors affecting the accounting information quality in commerce companies in the city.

\section{Literature Review}

As in [1], the study surveys of leaders of state agencies in Indonesia. The research results confirm that the understanding of the chief accountant and the support of the senior management affects the accounting information system. The accounting information system affects the accounting information quality. The author builds a model of some factors affecting the quality of the accounting information system.

The research [2] was conducted in the public sector in Indonesia. The objective is to determine the influence of factors on the quality of the accounting information system and its impacts on the accounting information quality. The results obtained from the study confirm that the factors of management commitment, organizational culture, and organizational structure directly affect the accounting information system, the accounting information system has an impact on the quality of the accounting information system.

As in [3], the quality of the accounting information system is measured by a combination of two criteria: system quality and information quality. The author's research has contributed to the development of a more basic theoretical framework on the accounting information quality systems in the environment of small and medium-sized companies in Hanoi, thereby improving the accounting information quality.

As in [4], the research results have created a strong theoretical foundation on the impact of some factors on the accounting information quality in the ERP environment. However, there are still shortcomings in measuring and testing 
the impact of these factors on the accounting information quality.

As in [5], the author focuses on understanding the impact of corporate governance characteristics on the accounting information quality of listed companies in Vietnam. The results show that all 7 factors of corporate governance have an impact on the accounting information quality of listed companies.

As in [6], the study identifies the factors affecting the accounting information quality of listed companies in Vietnam. The results have confirmed that 5 factors that directly affect the accounting information quality on the financial statements of listed companies. This study has a reference value on the theoretical basis in the field related to information on financial statements.

As in [7], the author asserts that the accounting information quality with additional attributes is more important than the basic attribute in the accounting information quality in the financial statements of listed construction and installation companies. It is further confirmed that listed construction and installation companies, who are audited by Big4 and those long-standing and large-scale companies have a better accounting information quality on financial statements.

As in [8], the objective of the study is the quality of financial reporting information in Vietnamese companies. This study is the theoretical foundation on the impact of factors on the quality of financial reporting information of companies.

\section{Research Methods and Models}

\section{A. Research methods}

In this study, the authors mainly choose the quantitative research method because the factors of the model have been built on previous studies, been measured, and tested through many studies in and around the world.

Quantitative method: the authors have used an online survey tool via email designed by the Google doc tool, then made statistics with Excel and SPSS 20.0. A survey questionnaire is built on a Likert scale with 5 levels (according to increasing agreement): (1) Strongly disagree; (2) Disagree; (3) Neutral; (4) Agree; (5) Strongly agree. After that, the survey results will be collected for analysis through SPSS 20.0 software combining several methods such as descriptive statistical analysis, reliability analysis, exploratory factor analysis (EFA), and linear regression analysis.

\section{B. Research model and regression equation}

In the study, the authors used the exploratory factor analysis (EFA) model to determine and test the relationship between factors (independent variables) affecting the accounting information quality in trading companies in Hochiminh City (dependent variable).

The authors inherit from previous studies to propose a group of factors (independent variables) affecting the accounting information quality in trading companies in Hochiminh City includes the involvement of managers, tax policy, internal control system, application of information technology, qualification of accountants.
Based on the proposed theory, the regression equation is expected to reflect the correlation between the factors affecting the accounting information quality at trading companies in Hochiminh City. The regression equation is as follows:

$\mathrm{CL}_{\mathrm{i}}=\alpha_{0}+\beta_{1} \mathrm{QT}+\beta_{2} \mathrm{TU}+\beta_{3} \mathrm{KS}+\beta_{4} \mathrm{CN}+\beta_{5} \mathrm{TD}+\delta$ Of which:

- CL: dependent variable describes the accounting information quality in trading companies in Hochiminh City

- QT: involvement of managers

- TU: tax policy

- KS: internal control system

- CN: application of information technology

- TD: qualification of accountants

- $\boldsymbol{\alpha}_{0:}$ intercept factor

- $\boldsymbol{\beta}_{1}, \boldsymbol{\beta}_{2}, \ldots, \boldsymbol{\beta} 5$ : regression coefficients

- $\boldsymbol{\delta}$ : standard deviation.

Research hypothesis:

+ Hypothesis H1: The involvement of managers has a favorable influence on the accounting information quality.

+ Hypothesis H2: Tax policy has a favorable influence on the accounting information quality.

+ Hypothesis H3: Internal control system has a favorable influence on the accounting information quality.

+ Hypothesis H4: The application of information technology has a favorable influence on the accounting information quality.

+ Hypothesis H5: Qualification of accountants has a favorable influence on the accounting information quality.

\section{Research Results and Discussion}

\section{A. Research results}

Testing quality of the scales

The results of analyzing the quality of the scale with Cronbach's Alpha coefficients

\begin{tabular}{|c|c|c|c|}
\hline Scale & Variables & $\begin{array}{c}\text { Cronbach's } \\
\text { Alpha }\end{array}$ & Conclusions \\
\hline QT & None & 0,834 & Good \\
\hline TU & None & 0,897 & Good \\
\hline KS & None & 0,873 & Good \\
\hline CN & None & 0,837 & Good \\
\hline TD & None & 0,860 & Good \\
\hline CL & None & 0,899 & Good \\
\hline
\end{tabular}

(Source: compiled by authors)

The scale reliability of the variables is of good quality and Cronbach's Alpha coefficient is $>0.8$ and up to 1 , the author concludes that the scales have good quality, high reliability, and are of good use.

Exploratory factor analysis (EFA) for independent variables

\begin{tabular}{|l|l|r|}
\hline \multicolumn{3}{|c|}{ KMO and Bartlett's Test } \\
\hline \multicolumn{2}{|c|}{ KMO (Kaiser-Meyer-Olkin of Sampling Adequacy) } & 0,751 \\
\hline \multirow{2}{*}{$\begin{array}{l}\text { Bartlett's Test of } \\
\text { Sphericity }\end{array}$} & Approx, Chi-Square & 235,610 \\
\cline { 2 - 3 } & Df & 3 \\
\cline { 2 - 3 } & Sig, & 0,000 \\
\hline
\end{tabular}

(Source: SPSS)

The results of exploratory factor analysis (EFA) of the dependent variable with the scale with the coefficient $\mathrm{KMO}=$ 
0.751 are suitable, reaching the conditions of $0.5<\mathrm{KMO}<$ 1 and Sig. $=0.000<0.05$. This proves that the survey data meets the conditions of exploratory factor analysis (EFA). From there, it is possible to determine the observed variables that are linearly correlated with each other in the accounting information quality in trading companies in Hochiminh City. The scales are appropriate.

Exploratory factor analysis (EFA) of the independent variable

\begin{tabular}{|c|c|r|}
\hline \multicolumn{3}{|c|}{ KMO and Bartlett's Test } \\
\hline \multicolumn{2}{|c|}{$\begin{array}{c}\text { KMO (Kaiser-Meyer-Olkin of } \\
\text { Sampling Adequacy) }\end{array}$} & 0,836 \\
\hline \multirow{3}{*}{$\begin{array}{c}\text { Bartlett's Test } \\
\text { of Sphericity }\end{array}$} & $\begin{array}{l}\text { Approx, Chi- } \\
\text { Square }\end{array}$ & 1695,920 \\
\cline { 2 - 3 } & Df & 210 \\
\cline { 2 - 3 } & Sig, & 0,000 \\
\hline
\end{tabular}

(Source: SPSS)

According to the above results, all the conditions for exploratory factor analysis (EFA) are satisfied. The coefficient scale $\mathrm{KMO}=0.836$ is good, satisfying the conditions that $0.5<\mathrm{KMO}<1$ and Sig. $=0.000<0.05$. This proves that exploratory factor analysis (EFA) is consistent with the actual survey data of the topic. That is, the reliability of the scales in the research model on the factors affecting the accounting information quality in trading companies in Hochiminh City is suitable.

Testing multivariable linear regression model

Multivariable regression test results

\begin{tabular}{|c|c|c|c|c|c|c|}
\hline & & & & \multirow[b]{2}{*}{$\mathbf{t}$} & \multirow[b]{2}{*}{ Sig. } \\
\hline & & B & $\begin{array}{c}\text { Std. } \\
\text { Error }\end{array}$ & Beta & & \\
\hline \multirow{6}{*}{1} & (Constant) & $-1,821$ & 0,261 & & $-6,990$ & 0,000 \\
\hline & TU & 0,270 & 0,046 & 0,278 & 5,931 & 0,000 \\
\hline & QT & 0,457 & 0,068 & 0,306 & 6,679 & 0,000 \\
\hline & $\mathrm{KS}$ & 0,179 & 0,053 & 0,162 & 3,357 & 0,001 \\
\hline & TD & 0,326 & 0,058 & 0,272 & 5,577 & 0,000 \\
\hline & $\mathrm{CN}$ & 0,257 & 0,056 & 0,229 & 4,630 & 0,000 \\
\hline
\end{tabular}

(Source: SPSS)

With the hypothesis of the research model, the results of testing the regression coefficients showed that all variables possess Sig values. $<0.05$. Thus, the research model consists of 5 independent variables: Involvement of managers (QT), Tax policy (TU), Qualification of accountants (TD), Application of information technology (CN), Internal control system (KS). All of these 5 independent variables and the dependent variable (the accounting information quality at trading companies in the HCM city) are statistically significant.

Thereby, the authors built a standardized regression equation describing the variation of factors affecting the accounting information quality in trading companies in Hochiminh City as follows:

\section{Regression equation:}

\section{$\mathrm{CL}=\mathrm{TU} * 0,278+\mathrm{QT} * 0,306+\mathrm{KS} * 0,162+\mathrm{TD} * 0,272+$ $\mathrm{CN} * 0,229$}

To compare the influence of each independent factor, we base it on the standardized Beta coefficient. Accordingly, the larger the standardized Beta weight, the stronger the influence of that factor on the dependent variable. As seen in the regression equation, of the 5 factors affecting the accounting information quality:

1. Factor Involvement of managers has the strongest influence with the standardized Beta coefficient QT $=0.306$.

2. Factor Tax policy has the second strongest influence with the standardized Beta coefficient TU $=0.278$.

3. Factor Qualification of accountants has the third strongest influence with the standardized Beta coefficient $\mathrm{TD}=0.272$.

4. Factor Application information technology has the fourth-strongest influence with the standardized Beta coefficient $\mathrm{CN}=0.229$.

5. Factor Internal control system has the fifth strongest influence with the standardized Beta coefficient $\mathrm{KS}=0.162$.

Evaluate the relevance of multivariable linear regression model

The results show that the model has a satisfactory fit with $\mathrm{R}^{2}=0.809$, equivalent to $80.9 \%>50 \%$, so this is an appropriate model to use to evaluate the relationship between the dependent variable and the independent variables. However, to measure the fit of the linear regression model, researchers often use the adjusted $\mathrm{R}^{2}$ coefficient (Adjusted $\mathrm{R}$ Square). In this study, the adjusted $R^{2}$ coefficient $=0.801$ means that the linear regression model built is suitable for independent variables, explaining $80.1 \%$ of the change of the dependent variable, which is the accounting information quality.

\section{B. Discussions}

From the research results, all 5 groups of factors influence the accounting information quality on the financial statements of trading companies in Hochiminh City. With the above data analysis results, the author concludes that:

First, the involvement of managers

There is a positive impact on the accounting information quality at trading companies in Hochiminh City with a standardized Beta coefficient $=0.306$. Indeed, the participation of managers influences the accounting information quality in financial statements at trading companies in Hochiminh City. Actually, in today's diversified and difficult integration economy due to the epidemic (Covid-19), it is impossible not to deny the importance of managers in companies, because these are the leading of each business, their business decisions will directly affect the business situation of the company. For today's investors, they are very sensitive to the unusual changes of senior personnel of the enterprise, even a small change in the senior management board can have a great impact on the company's business.

Second, Tax policy

There is a positive impact on the accounting information quality at trading companies in Hochiminh City with a standardized Beta coefficient $=0.278$.

The tax policy affects the quality of the accounting information at trading companies in Hochiminh City. If the tax policy is clear and tight, the company complies well, and the tax authorities issue many policies to support companies, the higher the quality of the financial statements of the enterprise.

Promulgated policies need to follow closely and be consistent with current accounting standards and regulations, and update according to the general trend of the world. From 
that, we can see that the relationship between tax policy and accounting standards and regimes is always a matter of concern to the state. From the perspective of trading companies in Hochiminh City, this is also completely consistent with the current situation.

Third, Accounting staff qualifications

Accounting staff qualifications have a positive impact on the accounting information quality in trading companies in Hochiminh City with a standardized Beta coefficient = 0.272 .

The authors believe that the qualification of accountants affects the accounting information quality in financial statements at trading companies in Hochiminh City. The human factor is an important one for success in operating an organization. The capacity of accounting staff is reflected in their knowledge and ability to meet the requirements of accounting work. With the current 4.0 economy, accountants must always learn and update new accounting standards, thereby improving the accounting information quality in the financial statements.

Fourth, Application of information technology

Information technology application has a positive impact on the accounting information quality in trading companies in Hochiminh City with a standardized Beta coefficient $=$ 0.229 . Entering the digital technology era, every business is aware of the importance of information technology application and is widely applied in agencies, people, and businesses. The use of computers and information technology equipment to edit documents, browse the Internet, and serve professional work has become a daily necessity of most civil servants, public employees, and officials of various departments in the companies. On the other hand, using digital devices to communicate and exchange information becomes a common need of employees in the company.

The accounting industry is no exception, typically largescale businesses are now using enterprise resource planning (ERP) systems, which entails all accounting work through unified software.

Fifth, Internal control system

The internal control system has a positive impact on the accounting information quality in trading companies in Hochiminh City with a standardized Beta coefficient = 0.162 .

An effective internal control system has a positive effect on the accounting information quality. That means the more effective the internal control system, the better the accounting information quality will be.

Conclusion and Policy Implications

The standardized regression equation and its descending order according to factors affecting the accounting information quality in trading companies in Hochiminh City are as follows: 1. QT $(\beta=0.306), 2$. TU $(\beta=0.278), 3$. TD $(\beta=$ $0.272)$, 4. $\mathrm{CN}(\beta=0.229), 5$. KS $(\beta=0.162)$. Specifically described as below:

Standardized regression equation:

$$
\begin{gathered}
\mathrm{CL}=\mathrm{TU} * 0,278+\mathrm{QT} * 0,306+\mathrm{KS} * 0,162+\mathrm{TD} * 0,272+ \\
\mathrm{CN} * 0,229
\end{gathered}
$$

The authors' study hopes to make a positive contribution to improving the accounting information quality for busi-
Beta coefficients of the factors

\begin{tabular}{|c|l|c|c|c|}
\hline No & \multicolumn{1}{|c|}{ Factor } & Beta & Sig. & $\mathbf{( \% )}$ \\
\hline $\mathbf{1}$ & $\begin{array}{l}\text { Involvement of } \\
\text { managers (QT) }\end{array}$ & 0,306 & 0,000 & 24,54 \\
\hline $\mathbf{2}$ & Tax policy (TU) & 0,278 & 0,000 & 22,29 \\
\hline $\mathbf{3}$ & $\begin{array}{l}\text { Qualification of } \\
\text { accountants (TD) }\end{array}$ & 0,272 & 0,000 & 21,81 \\
\hline $\mathbf{4}$ & $\begin{array}{l}\text { Application of } \\
\text { information technology } \\
\text { (CN) }\end{array}$ & 0,229 & 0,000 & 18,36 \\
\hline $\mathbf{5}$ & $\begin{array}{l}\text { Internal control system } \\
(\mathrm{KS})\end{array}$ & 0,162 & 0,001 & 13,00 \\
\hline
\end{tabular}

(Source: compiled by the authors)

nesses in general and trading companies in Hochiminh City in particular.

Policy implications

The involvement of managers is the most influential factor $(\beta=0.306)$ on the accounting information quality in trading companies in Hochiminh City. In addition to information from managerial accounting, managers in trading companies also rely on information in financial statements to make business decisions for their companies. Financial statements provide a source of general information about the company's performance, so relying on this information will ensure more accurate and correct decisions.

To improve the accounting information quality of trading companies in Hochiminh City in particular and trading companies across the country in general, perfecting the tax policy system is extremely necessary. The tax sector needs to perfect, improve and modernize the tax administration structure. To improve its operational efficiency, tax officials must have management skills and professional qualifications.

The qualification of accountants affects the accounting information quality. They are the ones who directly gather documents, use methods to prepare financial statements. Accountants need to be responsible for accounting work, ensure honesty, be careful in accounting, and prepare reports. In the preparation and presentation of financial statements, accountants not only need to have experience but also skills. The preparation of financial statements should be assigned to long-term, experienced, and highly qualified accountants.

Information technology applications need to be implemented in a well-organized manner from each stage: user assessment, application selection, application deployment, and solving problems arising in the implementation process. The application of information technology should be carried out synchronously in all parts of the enterprise if the funds are sufficient. If not, the enterprise considers and sets out a unified roadmap to apply technologies in important departments, avoiding the case of applying many different technologies at the same time leading to conflicts between applications.

Trading companies need to develop an effective internal control department to be able to check the operations of the company, quickly detect mistakes of the management board as well as errors and weaknesses, limiting risks in operation.

\section{REFERENCES}

[1] A. R. Komala, "The influence of the accounting manager's knowledge and the top management support on the accounting information system and its impact on the accounting information quality: a case of Zakat institutions in Bandung," Journal of Global Management, vol. 4, no. 1, pp. 57-73, 2012. 
[2] Rapina, "Factors influencing the accounting information quality system and its implications on the accounting information quality research," Journal of finance and accounting, vol. 5, no. 2, 2014.

[3] V. T. T. Binh, "Research on factors affecting the accounting information quality systems in small and medium companies in Hanoi city," Hanoi City, 2020.

[4] N. B. Lien, "Identifying and controlling the factors affecting the accounting information quality in the application environment of enterprise resource planning (ERP) systems in Vietnamese companies," Hochiminh City, 2012.
[5] N. T. Nguyen, "The impact of corporate governance on the quality of financial reporting information in listed companies in Vietnam," Hochiminh City, 2016.

[6] P. M. Nguyet, "Determining and measuring the influence of factors on the accounting information quality presented in the financial statements of listed companies in Vietnam," Hochiminh City, 2014.

[7] D. T. Nhung, "Study on factors affecting the accounting information quality in financial statements of construction and installation companies listed on Vietnam's stock market," Hanoi, 2020.

[8] P. Q. Thuan, "Factors affecting the quality of financial reporting information in companies in Vietnam," Hochiminh City, 2016. 